\title{
Common Law Cognition and Judicial Appointment
}

\author{
J.E. PENNER*
}

This article explores jurisprudential issues relating to the appointment of judges in common law jurisdictions. After examining three competing versions of the legitimacy and limits of judicial lawmaking - namely, the positivist, the theoretical/Dworkinian, and what the author terms the "common law cognitive" - the author proposes that judges of constitutional courts should be popularly elected from among the citizenry at large and that judges of non-constitutional courts should be drawn from the legal profession though $a$ process of peer assessment.
Cet article explore les aspects de jurisprudence qui concernent la nomination des juges de common law. Après avoir examiné trois versions possibles de la légitimité et des limites de lélaboration jurisprudentielle, notamment le positiviste, le theorique/Dworkinian et, ce que l'auteur appelle "la common law cognitive ", l'auteur propose que les juges des tribunaux constitutionnels soient élus par les citoyens et que les juges des tribunaux non constitutionnels proviennent des milieux de la profession au moyen d'un système de co-évaluation.

\section{TABLE OF CONTENTS}

I. INTRODUCTION . . . . . . . . . . . . . . . . 683

II. THREE VERSIONS OF JUDICIAL EXPERTISE $\ldots \ldots \ldots \ldots \ldots \ldots 685$

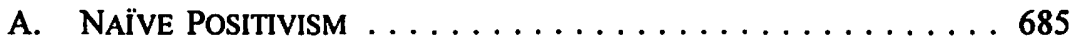

B. THEORTICAL EXPERTISE $\ldots \ldots \ldots \ldots \ldots \ldots \ldots \ldots 686$

C. Common law Cognition . . . . . . . . . . . . . 689

III. JUDICIAL APPOINTMENT $\ldots \ldots \ldots \ldots \ldots \ldots \ldots \ldots \ldots \ldots$

\section{INTRODUCTION}

In this article I want to examine what might be called some "jurisprudential" considerations that bear on the question of how we should decide to appoint judges in common law jurisdictions. In particular, I wish to consider the political power of judges, on the understanding that judges have political power just in so far as they do not merely interpret and apply the law, but make law. Now, of course, the distinction between interpreting/applying the law and modifying it is a difficult one.' In practice, officials of governments of all kinds, not only judges, must, in carrying out their duties prescribed by law, interpret the legal rules which are intended to govern their conduct with more or less leeway. All rules are more or less vague, and various rules may conflict in particular situations, and their interpretation and application in some cases will require judgment, and reasonable people will disagree as to whether any particular official's exercise of judgment is appropriate or correct in the circumstances. Nevertheless, the important point here is not a conceptual one about the interpretation and application of rules, but an institutional one, as Simpson makes clear:

Lecturer in Law, London School of Economics and Political Science. I am grateful to participants of the LSE Staff Seminar Series for comments on an earlier draft of this essay. I am also in debt to the faculty and students of the University of Alberta Law School, for encouragement and comments on a different paper discussing these arguments.

A good first step to analyzing the problem is reading Joseph Raz, The Authority of Law (Oxford: Oxford University Press, 1979) at c. 10. 
Plainly it is in principle possible to achieve the codifier's pure ideal ... and reduce the function of the judiciary to mere application. Indeed, very considerable bodies of statute law are in fact treated in just this way, or in something very closely approximating to it. For example, most English criminal law is administered by magistrates; large parts of the law so administered are statutory, and much of that innocent of case law.... Every day of the week countless decisions are taken by magistrates as to what counts as this or that, but the system is such that this activity generates no law whatsoever. Law is only produced when a case goes on appeal to the Divisional Court and beyond. It is important to see that the production of law through the interpretation of a text is not some sort of logical necessity, arising out of the nature of things; it is the result of the existence of certain types of legal institution, and if such institutions do not exist, the text can operate without giving rise to a mass of interpretive gloss.

Once it is seen how the interpretation of texts generates law, it is plain that to achieve the codifier's ideal one must attempt to prevent the evolution of any form of authoritative gloss; in the context of the common law this would mean in the first instance the deliberate reduction in the status of the higher judiciary. All judges must be reduced to the status of mere functionaries, as was attempted in France after the Revolution. ${ }^{2}$

In most common law legal systems, of course, only certain officials who interpret and apply rules are regarded as law-makers, viz, judges in the higher courts. There is no official cut-off point in the hierarchy of judges below which one is a mere lawinterpreter/applier, but practically the distinction is usually pretty clear, and is determined at the level at which cases are not reported, or less officially, not read as being authoritative. Neither, however, is law-making restricted to officials, in so far as courts or other officials are willing to accept as "authorities" academic or other commentators, i.e. as persons who may provide authoritative statements as to what the law is. The rule of recognition is, so to speak, a movable feast.

Making law, then, is not a function of interpreting and applying legal rules, but a function of what one says, either about what one has done oneself or about what others have done or about what ought to be done, in interpreting and applying rules. The power to make law is the power to state law, even if that is limited to "filling in" rules made by others. Higher judges, especially those on appellate courts, apparently have that power (that political power) in common law legal systems. What justifies their having it?

Where judges are not popularly elected for limited terms, no justification in the way of democratic legitimacy underpins such a power. The obvious alternative justification for their law-making authority is that lawyers and judges are believed to have some special sort of expertise which makes them particularly fit for making law. ${ }^{3}$ This seems

$2 \quad$ A.W.B. Simpson, Legal Theory and Legal History (London: Hambleton Press, 1987) at 393.

3 See Joseph Raz on the "normal justification thesis" of authority: J. Raz, The Morality of Freedom (Oxford: Clarendon Press, 1986) at c. 2-4. The basic idea behind this thesis is that A has authority vis-a-vis $B$ to the extent that $B$ is more likely to comply with the reasons that ought to govern his action by following the advice of $A$ than by trying him or herself to assess the reasons which ought to govern his or her action and acting in accord with his or her own deliberations. Such authority is most obviously provided where $A$ has expertise in an area. For example, if the question is a medical one and $A$ is a doctor. 
eminently reasonable, for lawyers and judges are professionally occupied with the doings of law, and should have a leg up on the rest of society in understanding how the law works, and therefore it might follow that this expertise will give them a better understanding of how the law might be modified for the better. However, explaining the nature of this expertise, especially in respect of how it might justify a law-making power, is not a simple task. I shall consider three possible descriptions of such expertise, under the headings "naïve positivism," "theoretical expertise," and "common law legal cognition."

\section{Three Versions OF JUdicial EXPERTISE}

\section{A. NaĨve Positivism}

"Naïve positivism," as I shall call it, is the view that the law consists of a body of laid-down rules, the "school rules" view of law, in Simpson's telling phrase. ${ }^{4}$ This model, while perhaps most apparently in tune with statute or codified law, is intended to apply equally well to common law: the body of common law is simply treated as that part of the rule book which has been laid down by judges over time in a piecemeal fashion in decisions made in the cases which have come before the courts. The primary duty of judges is to apply the rules as they exist. However, due to the vagueness of language, and possible conflicts between the rules, the rulebook is always, more or less, and more or less significantly, "incomplete." Cases will come before the courts in which the rule book, in its present state, does not determine the dispute in any straightforward way. Nevertheless, judges are required to decide a dispute in one way or another, and therefore they are empowered to decide the dispute despite the absence of determining guidance from the rulebook. Note that this empowerment of judges is not in any way required as a matter of principle as the appropriate solution to such difficulties. One might have created institutions that, where, according to a judge, the rules "run out" in this fashion, appeal is made to another body entirely, such as the sovereign or to a legislature, to modify the law authoritatively to decide the case. ${ }^{5}$ Besides having the power and the duty to decide the dispute, the decision of the judge may be regarded as the authoritative laying down of a new rule to cover relevantly identical cases of this kind. In this way, judges may be empowered and have the duty to modify, by way of supplementing, the previous body of law. Where judges state why and how they have decided in the way they did, that statement may itself be taken as a kind of authoritative modification, by way of supplement, to the previous body of law, i.e as the laying down of authoritative interpretive guidance for future decisionmaking.

What would justify empowering judges to supplement the law in this way? As far as this naïve positivist perspective goes, only the proficiency or expertise in working with legal rules gained from the practice of doing so. One used to bodies of rules

Supra note 2 at 364.

This, at least in the beginning, was the kind of solution adopted by the French legal system following the revolution. See J.H. Merryman, The Civil Law Tradition, 2d ed. (Stanford: Stanford University Press, 1985) at 39-41. 
would be used to seeing how they worked together as a system, would understand the conditional nature of many rules, their limitations and exceptions, and furthermore would come to understand the particular subject matter the rules addressed in so far as it was addressed by the rules, as in the rules of contract law, family law, and so on. Now, of course, different judges and lawyers will maintain different opinions as to the value or efficacy, moral, economic, or otherwise, of the various particular areas of law. And nothing in principle will govern their power to modify the law so as to prevent them from developing the law in the direction they find most appealing. But at least their opinions as to the best course of development will be informed opinions, in that they will know the surrounding rules, and the developments they make should work technically. That is, the new rules they make should be framed so as to fit in, more or less, with the surrounding body of law, since they know how rules can be made conditional, may be limited, may have exceptions, and so on. In short, they should be able to make new laws which are not likely to confuse the body of law. Furthermore, since the development of the law is fragmentary and unsystematic - judges may only make law in areas which touch on cases that come before them - this political power is mostly pretty meagre. Therefore, particularly in areas where the law as developed by judges is subject to correction through legislation by a democratically empowered institution, such as Parliament, the scope for the exercise of this political power is small enough not to worry very much about, and leaving to judges the incremental development of the law to deal with the inevitable problem cases as they arise is doubtless quite efficient. Much larger concerns arise as to the legitimating force of this expertise when it appears that the indeterminacy of the rule book is large, and the power of Parliamentary or other democratic correction of judicial decision is restricted or absent, as might be said of constitutional law. Here, however, it is important to emphasize the limited nature of the "expertise" lawyers and judges are supposed to have on this view. It is essentially expertise with a rule book, plus, of course, knowledge of the substantive rules of the book. It is not a very exalted expertise. In particular, judges are not conceived to have any particular expertise in determining what the rules ought to be; or rather, their expertise in this regard goes no further than knowing how one rule, as a specification of a direction in which it is desired to move the law, works better than another rule, a different specification, to best give effect to that legislative desideratum, given the way the rules work and the background rules into which the new rule must fit. While not an exalted expertise, it is also by no means trivial - if it were trivial, the job of the Parliamentary draftsman would be much simpler than it is.

\section{B. THEORETICAL EXPERTISE}

The legal theory of Ronald Dworkin probably best exemplifies this characterization of judicial expertise, though it is not limited to it. On this view, a judge's expertise goes beyond mere familiarity with the technique of guiding behaviour by rules. A judge is also a theorist of the substance of the rules, one who can provide a theory of why the specific rules are there, and can use this theory to deal with "hard" cases, cases where 
reasonable persons may disagree about what the rules actually dictate must be done. ${ }^{6}$ In Dworkin's own view, judges qua theorists are moral and political philosophers who have an obligation to develop and articulate, when need be, a theory of the substantive law, of the constitution, of statutes, of the common law, or more specifically a theory of the particular rights those different areas of law instantiate. But judges need not be theorists in this particular mould. Nothing in the conceptualisation of the judge as a theorist confines the theoretical approach a judge might take. He might be an economic theorist, or a sociological theorist, a theorist of any kind. What determines the judge to be a theorist is the outlook which he takes on legal doctrine. Legal doctrine, on this view, is justified only to the extent that it can properly be regarded as the concrete application of a more abstract theory in particular contexts.

Theory, in this context, refers to a certain use of highly abstract concepts as the ultimate ground of understanding. Whatever the concepts might be, justice, equality, dignity, efficiency, solidarity, alienation, and so forth, the force behind the analysis is supposed to lie in the fact that only by explicating such fundamental abstract ideas can more specific legal doctrine be justified. Thus justification is conceived from a very distinct perspective. The grounding of our understanding that something is right or wrong, praiseworthy or deficient, lies in our grasp of abstract, normative concepts. Yet these concepts are essentially contested, admitting of no straightforward articulation or explanation (much less definition). It takes prolonged, deep thought to bring our understanding of them to light. It is a quintessentially "academic" characterization of judicial expertise.

In consequence, in order to justify their decisions, judges must be capable of developing or adopting, but certainly themselves articulating, a theory or conception of some battery of abstract concepts which underpin the particular decisions they make in the instant case. While such a view is, perhaps, not widely accepted in most of the common law world, it appears to some extent to be almost conventional in the United States, whether in a Dworkinian "rights school" guise, or in the pervasive influence of economic analysis. For his part, Dworkin believes that before any judge of the Supreme Court be nominated, he must be able to articulate a well-worked out moral/political theory of the constitution, ${ }^{7}$ and that this inevitable exposure of law to the demands of philosophy raises genuine problems for the practice and study of law, since most lawyers and judges and even academic lawyers "have no time for the serious study of technical philosophy."

It is quite clear, on this sort of view, where judicial expertise lies. Besides the kind of fairly simple technical "rule-book" knowledge that is pointed out by the naïve positivist, judges also have a theoretical expertise, an expertise in developing and articulating the character of the contested abstract concepts in respect of which the law

Dworkin has expressed his views on many occasions, but perhaps his clearest statement of this thesis is found in "Hard Cases," chapter 4 of Taking Rights Seriously (London: Duckworth, 1977) at $81-130$. 
is justified. Though others besides judges may acquire this expertise, only judges are duty bound to both acquire and employ this kind of expertise as a function of their official position. As Dworkin says,

It does not follow from the fact that the man in the street disapproves of abortion, or supports legislation making it criminal, that he has considered whether the concept of dignity presupposed by the Constitution, consistently applied, supports his political position. That is a sophisticated question requiring some dialectical skill, and though that skill may be displayed by the ordinary man when he self-consciously defends his position, it is not to be taken for granted that his political preferences, expressed casually or in the ballot, have been subjected to that form of examination.?

For our purposes, the principle feature of this account is not that judges do not have a great deal of law-making power and political power. On the contrary, Dworkin is happy to acknowledge that they do, indeed that it would be "silly" not to. ${ }^{10}$ Furthermore, he is happy to regard different judges as being conservative or liberal judges, terms which are to be understood in the political sense. " What is to be emphasised is that the power of judges is one which is constrained by the technical, or logical and conceptual, demands of the theoretical analysis that is employed. The main advantage which is supposed to follow from this kind of law making, this sort of politics, is that it allows issues of great importance to be decided by principle, that is, by arguments and reasons which must meet some minimal level of theoretical articulacy, rather than by popular legislative politics.

Of course, no claim is made that adherence to these theoretical standards will avoid the making of mistakes in the creation of law. Theorists are not infallible. But what conclusions can be drawn from that?

The argument from judicial fallibility might be thought to suggest ... that since judges are fallible they should submit questions of institutional right raised by hard cases to someone else. But to whom? There is no reason to credit any other particular group with better facilities of moral argument; or, if there is, then it is the process of selecting judges, not the techniques of judging that they are asked to use, that must be changed. ${ }^{12}$

In this passage, it seems to me, Dworkin comes very close to saying that adjudication is the best way to engage in politics, at least in so far as the political activity concerns law making (as opposed, say, to a decision to declare war). That is, the process of making law is best carried out by persons who accept the technique of judges, who seek answers to difficult questions through the development of theories which provide illuminating conceptions of contested, abstract, fundamental concepts, whether or not they are styled judges or are selected in the normal way judges are. This, I think, is the reason Dworkin insists on such a sharp distinction (in theory, not necessarily in practice) between policy and principle. It would be wrong to deny that much

Supra note 6 at 129.

Ibid. at 127.

Supra note 7 at 284-86.

Supra note 6 at 130. 
government action of a goal-driven and pragmatic kind, such as the decision to subsidise an industry, is not carried out through law, i.e. through the legislation of legally binding rules. However, the principle/policy distinction reveals that such legislation is simply not theoretically tractable in the way "principled" law is, nor should it be expected to be, and furthermore that the generation of this kind of legislation should not be regarded as a problem for the theoretical characterization of judicial expertise. That expertise concerns "principled," i.e. theoretical, law; whether framed as constitutional law, statute law, or the common law, it is principled because it answers to a theory about the right relation of citizens to the state, a theory which is answerable to the rigorous theoretical demands of moral/political philosophy or some other theoretical perspective. One way of putting this is that Dworkin does not object so much to the idea that judges make law, but rather to the idea that judges are entitled to take policy decisions and effect them through law, i.e. make legally binding rules in the haphazard, pragmatic, policy-driven way that legislatures are entitled to do. ${ }^{13}$

\section{Common law legal Cognition}

The description of this third characterization of judicial expertise offered here is intended to go some way to give a modern cast to the common law legal theory described by Postema in the first several chapters of Bentham and the Common Law Tradition. ${ }^{14}$ The essence of that theoretical tradition resides in several particular elements: (1) the timelessness of the common law, i.e. the idea that the common law is in some way essentially unchanging; (2) that, perhaps in apparent opposition to this last point, that common law reason is artificial, not consisting of a universal and timeless set of moral norms; and (3) that the understanding of the common law is not "theoretical," but is more akin to a kind of wisdom acquired only by long experience.

How might such a set of theoretical commitments be defended today? The answer, I am going to propose, comes from paying rather close attention to what might be called "moral cognition," in particular the character of moral concepts. Only a basic sketch can be given here, so I must issue a rather substantial intellectual promissory note that the details can be convincingly worked out elsewhere. ${ }^{15}$ The central idea is that there are some basic moral concepts, concepts like murder, stealing, rape, malice, courage, cruel, kind, generous, and so on, which are fixed not by our history or culture, but by human nature, in particular by virtue of the cognitive apparatus human beings have. These concepts are acquired by us, largely in childhood, by exposure to goings on in the world that have moral significance. Without the grasp on morally significant aspects of the world that these concepts provide, there would be no way of thinking of things as morally right or wrong, good or bad, praiseworthy or base.

To understand how there can be a basis of moral cognition that is universally available to humans in virtue of their biology, which allows them to acquire a common

$13 \quad$ Ibid.

14 Oxford: Clarendon Press, 1986.

is For some more detailed preliminary work, see J.E. Penner, "Basic Obligations" in Peter Birks, ed., The Classification of Obligations (Oxford: Clarendon Press, 1997) at 81-122. 
set of basic moral concepts, yet at the same time explain how there can be cultural differences in morality, I draw a parallel with the acquisition of the grammar of a natural language, understood with the aid of some version of Chomskyan linguistic theory. From a Chomskyan perspective, the elemental building blocks of grammar (appreciating the verbness of verbs, the nounness of nouns, the basic logical concepts of not, and, or, and so on) are not learned by exposure to language, though exposure to language is necessary for acquiring them. They are innate to the kind of creatures we are. Innate mental structures provide parameters for the "growth" of different natural language grammars, in the sense that the innate structure provides parameters, different values of which must be selected in order to produce a consistent strategy of symbolic communication. Any natural language grammar can be described as a particular set of parametric selections. For example, subject, verb, and object, in a standard declarative sentence can occur in any order, and different languages "select" different orders. Similarly, the order of nouns and adjectives may be standardized either noun first, as in French, or adjective first, as in English. Some languages permit subjectless sentences, e.g. German (es regnet), others do not, so that dummy subjects (It is raining, $I l$ pleut) must be employed. ${ }^{16}$

On this view, the grammars of different natural languages represent grammatical variations, different structures built up from parametric selections between options determined by elements of the innate structure of the human mind. In the same way, and here is the parallel, my suggestion is that the actual moralities we find in particular cultures are variations built upon elemental building blocks, in this case basic moral concepts which are universally acquired given exposure to morally significant experience. ${ }^{17}$

The claim for basic moral concepts is the extension of one model of concept acquisition (largely due to the work of Fodor ${ }^{18}$ ) to moral concepts. The central idea is that concepts which represent features of the world that are acquired by an individual are not determined by that individual's subjective carving up of reality, so that the conceptual repertoire which any individual acquires might radically differ from that acquired by any other individual. Rather, aspects of the world "strike us," all of us, in

16 It is doubtful whether any actual natural language, such as English, can be definitively described via the elucidation of a single combination of parametric values. It seems rather that everyone to some extent speaks an idiolect, which differs not only in the size and specific items of vocabulary (obviously), but also in particular syntactic selections. Those who speak English are those whose communicative strategies or programmes consist of the selection of parametric values such that they can functionally communicate with members of a particular community of natural language speakers, each of whom can communicate with each of the others (by and large).

It is not the case, obviously, that exposure to moral experience means that, in order to acquire the concept murder, one must actually have witnessed a murder. Exposure to moral experience may be second-hand, through testimony, or through depiction of various kinds (stories, movies, etc.). The essential point about having a concept is that one is in a position to be able to recognize a murder when one is a witness to one (given adequate conditions of observation, and so on.) See J.A. Fodor, The Elm and the Expert: Mentalese and its Semantics (Cambridge: MIT Press, 1994) at $115-19$.

18 See J.A. Fodor, Concepts: Where Cognitive Science Went Wrong (Oxford: Oxford University Press, 1998). 
particular ways as a function of our general perceptual and cognitive capability, and acquiring a concept is very much like labelling the particular, "strikings," or gestalt impressions, which we experience. ${ }^{19}$ Thus, a substantial number of the concepts we acquire are not the creation of individual language users, nor are they the "products of culture" in a substantial sense (though of course the particular words in any natural language which express particular concepts, are); they are rather determined by innate characteristics of the human mind. Our conceptual repertoire, including moral concepts, grows upon exposure to experiences which are morally significant, because this exposure triggers or generates concepts which populate our moral vocabulary, concepts like murder, stealing, careless, and so on. Moral concepts are not "taught" any more than other parts of a child's conceptual repertoire are. As a result, there arises in the child a basic, untheoretical moral vocabulary in the same way that a child acquires all the rest of his basic untheoretical vocabulary. The claim is not of course that all concepts are acquired in this way; certainly "categorical imperative" and "proton" are not. Taking this perspective, Paul Churchland describes what goes on:

\begin{abstract}
Children come to see certain distributions of goodies as fair or unfair distribution. They learn to recognize that a found object may be someone's property, and that access is limited as a result. They learn to discriminate unprovoked cruelty, and to demand or expect punishment for the transgressor and comfort for the victim. They learn to recognize these and a hundred other prototypical social/moral situations, and the ways in which the embedding society generally reacts to those situations and expects them to react. ${ }^{20}$
\end{abstract}

Children acquire a diverse repertoire of moral concepts by exposure to certain kinds of stereotypical experiences-these experiences trigger the innate conceptual faculty of the mind so that children acquire stable concepts that can be applied to these experiences. Thus, despite the "poverty of the stimulus," that is, the paucity of cases to which children are exposed and the general lack of any kind of formal instruction, children acquire the same moral concepts, in much the same way as they acquire a great number of other basic concepts (concepts of trees, dogs, food, hugs, cold, dirty, and so on). By this triggering of our innate conceptual apparatus we are secured the basic "agreement in judgments" 21 over which moral reasoning and discourse can take place.

There are two particularly important aspects of this view that must be signalled. First, basic moral concepts, as the basic substance (and limit) of moral understanding,

For a detailed examination of the nature of concepts which considers both philosophical issues as well as the results of linguistics and cognitive science, see Fodor, ibid. For a discussion of the way that children acquire new words, words whose meanings they share with other members of their language community, at a remarkably rapid rate (so that Pinker says that they "must be lexical vacuum cleaners, inhaling a new word every two waking hours, day in, day out," and in the face of an extreme poverty of stimulus), see S. Pinker, The Language Instinct (New York: W. Morrow and Co., 1995) at 150-51.

P.M. Churchland, A Neurocomputational Perspective: The Nature of Mind and the Structure of Science (Cambridge: MIT Press, 1989) at 299, quoted in O. Flanagan, Self Expressions: Mind. Morals, and the Meaning of Life (New York: Oxford University Press, 1996) at 124. 
provide the means of creating a full morality, i.e. a moral understanding in which the moral relevance and content of any particular event or state of affairs can be grasped, in the same way that the elemental grammatical elements of language provide the means of expressing all of the things that can be expressed at all by creatures like us. It is an entirely open question how much of morality, i.e. how much of the particular set of moral beliefs held by any particular culture are determined by these building blocks; insisting on this characterization of the generation of moral conceptualisation does not prompt putting the nature/culture divide in any particular location. All that the present proposal demands is that the contribution of nature (nature qua the cognitive apparatus which provides this set of concepts) is significantly non-zero.

The second aspect of importance is the concreteness and plurality of these concepts. In respect of their concreteness, they are akin to the "thick" ethical concepts Bernard Williams describes:22 concepts which cannot fruitfully be analyzed into factual and evaluative components. To take courage as an example: one might analyze this concept and say that courage is personally dangerous risk-taking (the factual component), when that is a good thing to do (the evaluative component), whereas, in contrast, cowardice is the failure to undertake personally dangerous risk-taking (the factual component) where that would be a good thing to do, and foolhardiness personally dangerous risktaking when that is not a good thing to do. But the problem here is that these analyses strip the evaluative element of the concept down to an essentially vacuous "pro" or "anti" attitude or value - all the meaningful virtuous element of courage, the courageousness, is lost. Concepts of this kind are particular and local because our grasp of them is not the grasp of some abstract moral element that resides in certain events or states of affairs, but a gestalt grasp of a certain kind of event or state of affairs itself. This goes to explain why there is an irreducible plurality of these concepts, each corresponding to its particular concrete facts. On this view, the concept of moral does not refer to some very general property that one immediately finds or appreciates in different circumstances, which makes them morally relevant. Rather, moral is a theoretical construct that we have developed in order to make sense of the normative quality that things like courage and murder and malice and promise seem to share. Williams identifies his thick ethical concepts as being the most culturally specific ethical concepts. However a scan back over the examples he gives suggests, if anything, that these concepts will have the most universal instantiation. What human culture, for example, would not have acquaintance with and formed a concept of courage, or could not think about brutality or promises or greed? As far as I can tell, Williams gives no reason for regarding these concepts as culturally specific beyond the fact that they are "traditional," or "hyper-traditional" as he puts it. But because a battery of concepts has existed as a long-standing feature of a traditional culture does not entail that the concepts are specific to that traditional culture, but only that even members of traditional cultures can acquire them, i.e., these concepts are not restricted to moderns. Neither, however, are moderns excluded from acquiring them (which Williams seems clearly to imply, since by presenting them to modern readers in our language without quotes around them, surely he believes we have the concept of courage, brutality, and so on). If thick ethical concepts are equated with basic moral concepts, we see why all this is so - these concepts can be acquired by anyone who is exposed to stereotypical instances of events/experiences of the morally significant situations which they represent, and this means that they will be acquired by almost everyone, i.e. universally, since these events/experiences are as common as dirt. 
An important aspect of the concrete, local, character of basic moral concepts can be shown by again making reference to the culture/nature distinction. According to the view by which concepts like courage can be analyzed without remainder into a detailed descriptive component and a "thin," simple, "pro" or "anti" evaluative component, it is easy to treat all of the world-guided, i.e. natural, aspect of these concepts in the descriptive component. While culture in part helps determine the shape of this descriptive side, e.g. what particular cases of human agency fulfill the description of murder, it is plausible to regard what counts as an intentional killing as largely determined by certain natural or scientific facts about death, human intentionality, and so on. However, when one comes to the evaluative component, the substance is much more easily regarded as entirely cultural. The descriptive aspect of courage or murder may more or less track cultural- or mind-independent reality, but the evaluative component is purely a matter of the attitudes we have been acculturalized to take to these sorts of things. In short, if one adopts the view that ethical concepts like courage or murder can be analyzed into a rich, descriptive component and a thin evaluative attitude, it is much easier to believe that, though there will be some cultural influence in the characterization of the descriptive side, all of the natural aspect lies on that side of the analysis, whereas the evaluative component is cultural through and through. In contrast, the view proposed here treats these concepts as descriptive and evaluative wholes, so that wherever the nature/culture line is drawn, it will apply equally to these wholes, not disparately to descriptive and evaluative components precipitated out of an analysis.

Assuming that we acquire a battery of basic moral concepts in this way, why does that not imply that there ought to be no moral controversy, at least amongst those who have been normally exposed to moral experience during their development? Despite the broad claims made by some anthropologists and others in the past, it now appears to be the case that there are human moral universals, i.e. that all human cultures have concepts like property, rape, murder, and so on. ${ }^{23}$ Nevertheless, the existence of such a battery of basic moral concepts does not entail that there will be no cultural variation in morality. This follows from the limitations of the determining character of concepts acquired through exposure to stereotypical instances. The acquisition of a concept is a bit like opening a file on a research project. Our grasp of something through its stereotype anchors our concept to that thing, so that we maintain a grip on what the concept represents, the "thing in the world" we are thinking about when we use that concept. But that link does not make us all-knowing about that thing. Acquiring the concept dog allows us to think about dogs; but merely having that concept dog does not in any way tell us all there is to know about dogs. Indeed, it is not clear that it

See, e.g., D.E. Brown, Human Universals (Philadelphia: Temple University Press, 1991). Of course this evidence does not by itself indicate the existence of an innate faculty which is triggered by experience to produce basic moral concepts - it could be just that, as a matter of fact, all cultures experience disputes over goods, coerced sexual intercourse, and so on, and that the appreciation of moral categories like property and rape arises as a function of humans' general intelligence applied to make sense of this experience. It is the cognitive science evidence regarding the structure and acquisition of concepts in general (as well as certain critical or philosophical considerations which concern the interpretation of that evidence) which suggests that the innate conceptual apparatus story is a plausible one. See Fodor, supra note 18. 
generates any necessary true beliefs about dogs, beyond the trivial belief that that (some dog before us) is a dog. As we learn about the things our concepts represent, we learn to apply our concepts beyond their stereotypical instances on the basis of those further beliefs. For example we learn that non-stereotypical dogs that might at first strike us as more like rats, say chihuahuas, are actually dogs, and so apply the concept dog to them accordingly. Similarly, we acquire the concept property for instance from exposure to stereotypical situations where this mode of behaviour in dealing with things is instantiated. But we do not rest content with that. We come to believe things about property, and these beliefs will contribute to our understanding about the true nature of property, ${ }^{24}$ and thus the appropriate scope of the concept.

For example, an obvious belief one may quickly form about property is that, functioning to allow individual owners the exclusive determination of the disposition of what they own, they can use what they own for their own benefit. But forming this belief has consequences. One might conclude that property which is not being used by the owner should no longer be his. Thus by coming to believe that property has a particular rationale, one may come to believe something about the scope of the concept. One may come to believe that property that is not being used by a purported "owner" is not truly his property. The point is that there may be nothing in our grasp of the stereotype which allows us to settle the issue of what happens when an "owner" never uses what he purports to own. Coming to form beliefs about the nature of property, yet throughout relying upon our conceptual grasp of its stereotypical instances is, in a sense, an exploration of our psychological connection to the world of property-relevant circumstances, or an exploration of our moral psychology as revealed by our grasp of such a stereotype. We may, of course, form true or untrue beliefs, ${ }^{25}$ and as a result individuals or communities which share an innate conceptual grasp of property may disagree about its true nature and thus the content of the concept which represents it. To take an example of a contrary belief about property which leads to a conclusion opposite to the one above, an individual or community may come to believe, like Hegel, that the real explanation of property is that it serves to actualise or make

I discuss the concept of property because I am familiar with it. See, e.g., The Idea of Property in Law (Oxford: Oxford University Press, 1997), "The Bundle of Rights Picture of Property" (1996) 43 U.C.L.A. L. Rev. 711. However, it is probably not the best example, for it may be the case that "property" in English actually specifies two fairly distinct basic moral concepts, viz, property in objects ("chattels" in legal terminology), and property in land. This is suggested by the fact that a land/chattels distinction is a typical feature of legal systems, but also because of the fact that the "prototypical" circumstances of concept acquisition of property (chattels) and of property (land) would appear to be sequential. That is, it seems reasonable to believe that children learn the "mine and thine" aspects of the objects which populate their world much sooner than they would the quite different territorial imperatives (no trespassing, and so on) underlying ownership of land. So it might well be the case that the term "property" has two quite distinct prototypical instances, so that the concept property is a higher order concept which covers two distinct (though clearly related) basic moral concepts. For that reason, in what follows, I shall suppose that property refers only to property in chattels.

25 If we assume confirmation holism (i.e. the idea that our beliefs are collectively confirmed as a corporate body before the tribunal of experience) then, of course, beliefs which might appear quite irrelevant to our present beliefs about property may, in fact, be relevant to their truth. 
manifest the personality of the individual in the world. ${ }^{26}$ Thus in various ways an individual's relationship with a particular thing through ownership establishes his existence, and his actual use of his property is only one possible manifestation of this relationship. One might thus conclude that to treat use as the only mark of property is to mistake its nature.

This picture of the application of our moral concepts, both as a result of our innate grasp of them and of our formation of beliefs about the properties they represent, is complicated by the fact that our basic moral concepts interact. Consider the concepts promise, harm, and property together. Our beliefs about promises, harm, and property may operate together in determining how we will assess what morality dictates in certain circumstances. For example, I can promise to make you a gift. Should I honour my promise to give you ten feet of rope if I now suspect you will hang yourself with it?

Moral discourse, on this elaboration, then, is in part a matter of reasoning about and justifying various beliefs, and so obviously modes of reasoning which test or demonstrate or give rise to beliefs, such as deduction, inductive inference, reasoning by analogy and from precedents, and so on, will apply here just as much as in any other discourse which considers the truth of beliefs. Furthermore, here the selection of parametric values on the quasi-Chomskyan perspective on morality comes into play, in particular as regards the development of the common law.

Consider the possibility that what we, as lawyers, over time have done is to apply the basic moral concepts we have to actual cases, in the course of which we will have explored the nature of the (moral) properties these concepts represent, and in doing so will have adopted various beliefs about these properties, e.g. about the nature of property in chattels, for example. It is clear that in many cases troubling questions will have arisen, and will continue to arise, where our moral intuitions will cut both ways; that is, our grasp of the prototypical cases of the moral properties which our moral concepts represent does not allow us straightforwardly to apply these concepts to nonprototypical cases. In these circumstances, we will rely upon the beliefs we have formed about the properties these concepts represent and make decisions based upon those beliefs. Thus we move from a gestalt grasp of an experience, to a reflection of what our past experiences appear to teach us about properties, and decide cases trying to work out an answer which is coherent with the set of beliefs we have acquired. But one possible answer may accord as coherently with our intuitions and our current beliefs as another, i.e. appears to accord as far as we can tell, trying as hard as we can, given the limitations of time and intelligence. Here the law is genuinely unsettled. Here a judge must make a selection, and such selections, if they are regarded as authoritative developments in the law itself, have obvious consequences for the web of beliefs which constitute the body of law. Such selections amount to a path taken, and, as the law develops, such a choice will bring in train a wave of demands on the continuing coherence of the body of lawyers' beliefs. On this view, legal reasoning in actual cases 
is a matter of working out, within the constraints provided by our basic moral concepts, our "past commitments,"27 one way or another, in endeavouring to make moral sense.

There is an obvious analogy here with the selections which particular languages make amongst the various syntactic parameters. The idea is that while our basic moral concepts do not determine the morally correct answers to all disputes, they do constrain the selection of decisions in areas where our intuitions run out, and constrain them in parametric ways. In other words, once having made a selection that takes us in a particular direction, we will not only have determined a series of subsequent decisions, but will have shaped in a particular way the structure of beliefs, in particular the way in which different moral properties, like property in goods and contracts, for example, are understood to interact, say in contracts of bailment.

One of the most obviously socially constructed cases of parametric selection which the law undertakes is the case of a selection made for institutional purposes, often by a legislature. For example, in most common law countries, the legislature has placed formality requirements on a number of dispositions of property, upon wills, contracts for the sale of land, and so on. As a result, informal transactions entered into by parties fully intending them to be effective are either unenforceable or void. Even though there are good reasons for these requirements, it is clear that they can do injustice in particular cases. In consequence, therefore, of this formalities "selection," a great many cases have been devoted to defining the contours of the requirement given the opposite pressure from the belief that intentional dispositions should not be defeated. ${ }^{28}$ Other obviously institutional selections concern rules of evidence and the forms of remedial relief. Each has clearly affected the development of the substantive law.

It is beyond the scope of this paper to go into a catalogue of examples to show the way in which particular selections have this parametric quality, although providing such examples and showing how they generate a plausible characterization of the common law across the broad sweep of its historical development is the ultimate proof of this pudding. To give but one more example of this sort of "parametric selection" analysis, consider the concept of the trust. The trust is peculiar to common law jurisdictions deriving their legal doctrine from the law of England. The law of trusts can be conceived as part of the law of property, and indeed this is the orthodox analysis. However, it is clear that the trust arose as a particular kind of obligation with respect to property which the courts of equity would enforce. The proprietary character of the trust flows from Equity's willingness to extend the trust obligation to various third parties who were never intended to hold the property as trustees, and in this way, the trust relationship, and thus the beneficiaries' interest in the property, was held to bind all the world, minus certain important exceptions. However, it would not have been

"Working out our past commitments" is a phrase of Arthur Ripstein's. I have tried here to give it a content which serves my purposes, of course, and I beg forgiveness if I have abused the meaning he intended to give it. 
"incorrect," nor is it now "incorrect" in civilian countries which do not recognize a trust concept, for the common law not to have allowed the trust obligation to escape the law of obligations and create a novel sort of proprietary relationship. However, once having "selected" a proprietary trust concept, distinct conceptual consequences follow. For example, on the proprietary view of trusts it simply follows as a matter of course that a trustee's creditors are not entitled to property that she holds on trust should she go bankrupt-the beneficiaries are the owners of the trust property, so it simply cannot form part of the trustee's estate in bankruptcy. Or, to take another example, the creation of a trust by a settlor amounts to a disposition of his property, so that the beneficiaries become the owners, and this has the clear consequences that, though the property was the settlor's, he cannot regard it as "still his" once he has placed it in trust. He is not like one party in a contract for the benefit of a third party, who retains rights under the contract. Thus Waters rightly says:

\begin{abstract}
...the trust is a mode of disposition, and once the instrument of creation of the trust has taken effect or a verbal declaration has been made of immediate disposition on trust, the settlor has alienated the property as much as if he had given it to the beneficiaries by an out-and-out gif. This almost selfevident proposition has to be reiterated because it is sometimes said that the trust is a mode of "restricted transfer." So indeed it is, but the restriction does not mean that by employing the trust the settlor inherently retains a right or power to intervene once the trust has taken effect, whether to set the trust aside, change the beneficiaries, name other beneficiaries, take back part of the trust property, or do anything else to amend or change the trust. By restriction is meant that he has transferred the property but subject to restrictions upon who is to enjoy and to what degree. The mode of future enjoyment is regulated in the act of transferring, but the transfer remains a true transfer. ${ }^{29}$
\end{abstract}

Two points, I think, can now be made clear. The first is that the extent of the analogy of the developmental history of the common law with the developmental history of a natural language, while illuminating, is also limited. The Chomskyan characterization of the syntactic parameters of natural languages, are, according to the theory, "hard-wired" in a different way than are the parameters giving points of selection in the development of legal systems. While the claim is that the basic moral concepts underlying moral cognition are "hard-wired," their application both in cases outside their stereotypical cases and where the moral intuitions delivered by such concepts cut both ways is not a matter of the selection of one or other parametric value embodied in the battery of basic moral concepts themselves, or at least, this is not obviously the case. Their application in such cases will depend for the most part on the beliefs we have formed about the nature of the things these concepts represent, what we believe about property, murder, and so on. In this way, though legal parametric selections might have been otherwise, these selections are not arbitrary in the sense that there is a defined and limited array of parametric values, one of which must be chosen, and for which choice no reasons need be given. To the extent that a choice is wholly a matter of parametric selection, no conclusive moral or legal reason may be given for it. It is akin to the parametric syntactic selection of placing adjectives before the noun rather than vice versa (in circumstances where this selection is not already influenced or constrained by another selection). To be sure, some legal choices do seem to be 
largely arbitrary in this way. For example, it seems to me that a legal selection whether or not to impose formalities requirements on certain transactions and if so, which particular type to adopt, is much like the adoption of a social convention, like choosing to drive on the left rather than the right. ${ }^{30}$ However, in making the selections, one adopts a kind of strategy in regard to the validity of property transactions which does give rise to further moral, and thus legal, considerations. In favour of formalities, one can say that they provide good evidence and that they caution individuals. People normally treat written documents which they must sign as importing something of legal consequence. Opposed to this is that oral evidence is often perfectly adequate, and that people may be justly bound by their intentional actions regardless of whether, in retrospect, they took sufficient time for consideration.

The force of the parameters analogy lies in the systematic aspects which flow from the development of legal doctrine which is ultimately secured by a fixed set of basic moral concepts. Particular legal selections constrain subsequent ones. Our beliefs concerning the nature of the properties our moral/legal concepts represent and our understanding of the consequences of our past parametric selections will, it is submitted, provide sound reasons for making subsequent parametric selections in one way rather than the other. In these cases, selections which are wholly parametric for one legal system, in that the sound beliefs concerning moral concepts and the past commitments of that system do not determine the selection to be made, may be wholly determined by the beliefs and past commitments in another system. So, for example, under orthodox trust law, the necessity of the particular "selection" or determination which Waters articulates in the passage above can hardly be gainsaid. And the analogy with the parametric selection of syntactical elements of a language continues in so far as with regard to one's knowledge of the grammar of one's natural language. While people who speak a natural language know, by definition, its grammar, this knowledge can rarely, if ever, be articulated by native speakers as a systematic body of rules for communication. Similarly, a lawyer's or a judge's unarticulated wisdom, or "grammatical sense" of the body of law, will push him or her in one direction rather than another. Indeed, this "grammatical sense," developed from diligent attention to long experience, may be the most important facet of anyone's being a good judge or lawyer. This is not to deny the importance of demanding from lawyers and judges the most rigorous and precise articulation of their judgments that they can muster. But the essence of relating a body of law to a foundation in basic moral concepts which we have, as it were, for free, i.e. available to us without having had to produce them ourselves through some philosophical or scientific act of creation, is that, in a very substantial sense, the development of the law will be more like an art than a science. Thus, a humane law will be the product of the efforts of sensitive, circumspect practitioners faced with the task of trying to treat like cases alike, answering to a host of considerations generated both by past explorations of the way that basic moral concepts guide our sense of what is just and by the myriad context-bound conclusions 
we have made concerning the coherent systematisation of these considerations. In this way, a good lawyer or judge is like a good interpreter of literary texts - pointing out various features of what is said, relating those to the various circumstances of their production, to weave his way through a body of decisions to provide a compelling understanding. The task will forever result in doctrine which is more or less provisional; certain schemes of conceptual organization which for a time will appear certain (certain in the sense that they seem to make solid good sense of our moral understanding across a range of cases and which fits coherently into the large picture) will become unsettled as more is understood of the actual character of the properties our basic moral concepts represent. As Simpson says, "The point about the common law is not that everything is always in the melting-pot, but that you never quite know what will go in next."31

The parametric selection analysis illuminates, it is hoped, several features of the institution of law. It explains why learning the law, though essentially dependent on nothing more than the student's grasp of our common basic moral conceptual repertoire and the common modes of human reasoning, does involve the analysis of cases, and frankly, brute memorisation of the past selections which the law has made. Learning the law is not only a matter of refining our beliefs about the properties our moral concepts represent through their application to real cases, but also requires an indoctrination in the various parametric or grammatical choices of the particular body of law in question. Thus learning the law is assimilating our past doctrinal commitments, and involves the analytic attempt to make as much sense of this body of commitments as can be made, while at the same time understanding that certain of our selections and past commitments are ever provisional, and that at any time certain of them may not stand together well, creating doctrinal conflict.

The notion of parametric selection also underscores another aspect of the institutionalisation of the law in common law countries. For doctrinal refinement by parametric selection by judges in particular cases to work, this judge-made law must be preserved by an institutional memory. Without it, the various parametric selections cannot be retained, and doctrinal coherence cannot be preserved. The institutionalisation of this memory can be achieved in a number of ways, from creating a small caste of jurists who preserve and transmit their knowledge in an oral tradition through constant joint consideration of legal issues, or more obviously today, through preservation by a written record. A great deal needs to be said about this, though a fruitful starting point is undoubtedly the thoughts of A.W.B. Simpson. ${ }^{32} \mathrm{He}$, as far as I am aware, is the only one who has seriously addressed the way in which issues like the decline of the jury trial (by no longer requiring judges to state the terms of the law in a way which actually guides laymen, the creation of a mass of abstract law may be facilitated which, to say the least, may obscure our application of basic moral concepts, rendering the whole unstable), the massive increase in the numbers of judges (so that each judge is not regularly in contact with all the others in remembering, applying, and developing

$31 \quad$ Supra note 2 at 373.

32 In particular his "The Common Law and Legal Theory" and "The Survival of the Common Law System," both in Simpson, ibid. 
legal doctrine), and the rise of legislation as a source of law, may all contribute to a decline in a workable institutional memory capable of preserving the integrity of the sort of judge-made law described.

Now, I think, we can return to the three elements of common law legal theory identified by Postema. The common law is timeless or essentially unchanging in that it forever has the same object or subject matter, the exploration in cases of conflict of our basic moral concepts with a view to appropriately providing normative guidance to subjects of the law. Furthermore, the law can be thought of as being discovered and declared, rather than made, because our essential grasp of the moral issues in play determines, to a large extent, the appropriate normative guidance. In this way, the common law is timeless and unchanging. On the other hand, the law is clearly the historically changing product of artificial human reason. Lawyers and judges are not given by nature any systematic body of doctrine: that arises from the "selection" of different conceptual specifications in a specific institutional context (which itself obviously changes over time). Finally, the common law is not theoretical, the product of abstract philosophical or other sorts of theorising: rather, it remains wedded by necessity to exploring the guidance provided by an irreducibly plural set of basic moral concepts. The analogy with language is now sharpened. Human natural languages are both unchanging and undergoing constant change - unchanging in their universal grammatical basis, but constructed by an "artificial reason" into the many different actual natural languages we see, each of which is itself very resistant to sudden change. To know English is to know a communicative strategy which partakes of the universal but which also has its own long history. Furthermore, while all native speakers possess their language equally in the sense of having all the grammatical rules under their belts, not everyone is equally articulate, and in particular, equally capable of speaking and writing well. And coming to do either is not to acquire a theory or a set of facts, but to acquire an artificial reason through long experience, trial and error. This depends to some extent on native talent, something like a craft capability, which allows the good speaker or writer to express well, persuasively, evocatively, precisely, and compellingly, those thoughts which are, for one reason or another, difficult to express, to pin down, and to fix in language. Similarly, one may suppose, lawyers and judges acquire facility with the artificial reason of the law not through amassing a body of facts or learning a theory, but by developing a practical familiarity and facility with the battery of concepts and the doctrinal system in which these concepts have been limited and shaped and organized into some more or less coherent body of considerations which may be prayed to in aid to give normative guidance to the subject of the law. Thus the "school rules" model of the law is clearly inapposite. Simpson's and Simmond's claim $^{33}$ that the common law does not seem to be a body of rules at all is not, as I understand it, that judge-made law consists of a body of rules of varying abstraction in no orderly system, but that it is a body of examples, of cases, of the application of a certain way of thinking. Thus one understands judge-made law in the same way one comes to understand English or French literature, by spending a long time looking at examples where it has been done, and by acquiring the faculty of doing law and doing 
literature by practice. On this view, the basic rationale for teaching law through judicial decisions, by reading cases and by exploring and criticising the way that decisions were made, is that this provides the student with a kind of telescoped experience of actual legal practice.

A few final, but important, points, must be added to fill out this characterization of what I have called common law legal cognition. First, it should be clear that this kind of legal cognition cannot apply to the full range of judicial decision-making. It can occur only in those areas of law governed by rules which more or less turn on the kind of normative grasp provided by basic moral concepts. It is no surprise that reference to the specificity of the concepts at work has most prominently featured in the work of criminal law theorists. ${ }^{34}$ Duff in particular argues that for the criminal law really to be the law of any community, it must operate through thick ethical concepts which have a reality for the subjects of the law. ${ }^{35}$ I can only submit here that I think a similar kind of case can be made for the basic moral concept-guided quality of areas of law like torts, contract, and property. Wherever one might wish to draw the line, however, I think it quite clear that no such case can be made for a great deal of the law that governs subjects in any modern western legal system. The point is not that a certain common law quality of thinking and reasoning may not extend into such areas, but rather that no resource in basic moral concepts provides any timeless anchor that determines the basic shape of the way any normative guidance is conceptualised. Modern constitutional law is an obvious case of this sort, for it seems quite clear that the concepts which are regarded as central and important, such as rights, democracy, equality, liberty, and so on, are not even plausibly the result of basic moral cognition, but are hard won historically-traceable human intellectual achievements.

It should also be apparent that despite the name I have given to it ("common law legal cognition"), this practice of elaborating the basic conceptual elements delivered by moral cognition is not exclusive to common law legal systems. Indeed, given the character of the foregoing it seems clear that both this cognition, and the artificial elaboration of it, is universal in the same way that all cultures produce natural languages on the back of elemental grammatical parameters. The conceptual apparatus of the roman civil law and its descendants equally rank as legal grammatical structures, equivalent counterparts to natural languages. Perhaps the most striking example in the civil law world of a theoretical grasp on this kind of cognition is the creation of "legal science" by the German Pandectists:

The concept of legal science rests on the assumption that the materials of the law (statutes, regulations, customary rules, etc.) can be seen as naturally occurring phenomena, or data, from whose study the 18 Oxford J. Leg. Stud. 189 and "Inclusion and Exclusion: Citizens, Subjects, and Outlaws" (1998) 51 Curr. Leg. Probs. 241; J. Horder, "Rethinking Non-Fatal Offences against the Person" (1994) 14 Oxford J. Leg. Stud. 335; J. Gardner, "Rationality and the Rule of Law in Offences against the Person" (1994) 53 Cambridge L.J. 502 and "On the General Part of the Criminal Law" in A. Duff, ed., Philosophy and the Criminal Law (Cambridge: Cambridge University Press, 1998) at 205-55. 
legal scientist can discover inherent principles and relationships, just as the physical scientist discovers natural laws from the study of physical data. ${ }^{36}$

The assumption of legal science that it scientifically derives concepts and classes from the study of natural legal data on the one hand, and the generally authoritarian and uncritical nature of the process of legal education on the other, tend to produce the attitude that definitions of concepts and classes express scientific truth. A definition is not seen as something conventional, valid only so long as it is useful; it becomes a truth, the embodiment of reality. ${ }^{37}$

The purpose of citing this example is not to endorse the theoretical assumptions and practice of legal science. What it reveals, however, is one (very particular) civilian counterpart to common law legal theory, one which is much more influenced by natural science methodology and the value of abstract systematising. The correspondence between them lies in the assumption that the substance of law lies in the pre-theoretical "data" of fairly concrete norms, which, like the data of natural science, reflect a basically unchanging normative reality. Legal science, though wholly different in methodology from that of common law legal theory, is likewise regarded as an exercise in understanding something which is essentially unchanging, and about which truths may be discovered and expressed.

\section{JUdiCiAl APPOINTMENT}

What has all of this to do with judicial appointment? The reason for raising the preceding characterizations is that it seems sensible, before designing an appointments process, to determine the character of the job to be done by the appointee, and thus the sort of expertise required to undertake the job. What the preceding characterizations of judicial expertise reveal is that, to the extent that a modern state allocates to adjudicative bodies law-making power in politically sensitive constitutional law areas (in particular law-making concerning the limits of legislatures and the scope of civil rights of the kind found in typical bills of rights), that only on the second version of judicial expertise, i.e. qua theoretical expertise, do judges have any particular expertise as law-makers. However, despite the claims to expertise the theoretical expertise school may make, the result in respect of judicial appointment is roughly the same, which is that the appointments process of adjudicators to make law in these areas ought to be properly politicised. By "properly politicised," I mean that such law-makers should be chosen for their posts by popular election.

According to the naïve positivist view, judicial expertise in law-making concerns the expertise of dealing with systems of rules. While, as previously pointed out, there may be a strong argument in favour of efficiency to allow judges, at least senior judges, to make law on an incremental basis (to "fill gaps" in the law, as it were), this argument only goes to those areas of law which are amenable to political correction through the legislature. It works best in areas which might be characterized as "lawyer's law": the workaday bodies of law which, when they are subject to legislative reform (which may 
of course involve matters which are politically contentious like criminal sentencing or divorce law), are typically reformed by legislative processes largely organized through the work of judges and lawyers through law reform commissions or committees. Where, on the other hand, the area of law concerns matters of the constitution, where the decisions of judges, in particular judges in the final court of appeal, are not subject to any regular legislative correction, there seems no justification by way of judicial expertise to grant this law-making power to judges even though the process of lawmaking is adjudicative (i.e. grows as a result of the decision in cases as they arise before an authoritative resolver of disputes). The reasoning behind this argument is not, I hasten to add, that judges are incapable of building up a complex and nuanced body of law in these areas; rather the opposite is surely the case. The reasoning is simply that the ability to build up a body of rules per se gives no legitimacy to the body of law developed. It may well be the case that there is a peculiar expertise that politicians qua legislators possess. In some way or another it may be the case, more or less, or hopefully, that only experienced or "expert" legislators make it to Parliament. Even so, no one attributes the legitimacy of the laws passed by Parliament to that. Whatever legitimacy the law-making of Parliament has is standardly attributed to the democratic/representative basis of the election of members to the office of legislator. In the same way that legislators are advised by lawyers in transforming their legislative initiatives into statutes that function as additions to the body of rules of law, it would appear sensible to appoint senior lawyers or judges as advisors to any body of adjudicative law-makers who rule on conflicts raising issues of constitutional import. But there seems no reason to restrict the class of candidates to the post of constitutional adjudicative law-maker to judges or lawyers. They, on the naïve positivist view, simply have no particular qualifications which would make them more equal than all the rest of the class of potential law-makers (i.e. the entire citizenry) to make momentous (i.e. very difficult to change) decisions of this kind. They have no special expertise, and neither are they somehow naturally better representatives of the citizenry - if anything, on the last score they are likely to be markedly unrepresentative.

What must be emphasised is that on the naïve positivist view of judicial expertise, judges have essentially no greater political legitimacy than anyone else. Their lawmaking role varies in political legitimacy inversely with its extent and importance. To the extent that it is doing more than efficiently filling gaps in the legislative will whose legitimacy arises from its democratic representative imprimatur, to that extent it begins to smack of illegitimate, quasi-factional usurpation of political power. While the naïve positivist characterization of judicial expertise may ultimately be wrong, it is certainly sensible. Indeed, such thoughts seem to have driven, for a time, the judicial place in the political settlement in France following the revolution. Thus the point of regarding constitutional or, perhaps, administrative law, as of especial importance is not that it is somehow law of a different kind, but that it is the essential foundational law of the extant political settlement, and therefore of supreme importance. In short, it is too important to be deprived of at least as great a democratic and representative legitimacy as any other form of law-making, for that democratic and representative legitimacy is supposed to underscore the justification of the political settlement itself, and constitutional law is the law of that settlement. 
A similar position arises from the characterization from judicial expertise as theoretical, but on a different basis. Judges' expertise is relevant, in an interesting way. As with the naïve positivism, judicial expertise is content-neutral in one respect judicial expertise applies to all areas of law in the same way, whether common law, statute law, or constitutional law - it is a way of deciding cases. But it is not contentneutral in a different respect. It is not legislative in the sense that judges have no expertise in advancing policy goals; therefore judges cannot decide cases in reference to those goals. So in this latter respect the law-making of judges cannot be contentneutral - it cannot endeavour to accomplish through law those desiderata which require the goal-setting capabilities of legislatures. It is important to recognize that though the principle/policy distinction of Dworkin is one way of capturing this distinction as to the content of laws, it is only one. For obvious reasons that distinction expresses nicely the difference between the principle-oriented adjudicative and the policy-driven legislative, given his allegiance to moral and philosophical theory. But similar distinctions would have to be developed for any theoretical characterization of judicial expertise. Were judges to adopt economic theory as their adjudicative standpoint, they would still be confined by the limits of economic theory. That would determine some issues, but advancing economic efficiency involves more than the application of theories in particular disputes. Legislative programmes intended to do so would have to be based upon empirical investigations of facts, which adjudicators are clearly inappropriately placed to undertake. Thus, like the Dworkinian judge, the economic theory-minded judge would equally realize that certain goals, while suitable to be achieved through law, would lie outside his province of law-making.

While it seems very likely that the actual limits vis-à-vis the content of laws which a moral- or philosophically-minded theorist might regard himself as capable of developing through adjudication would differ from those that an economically- or sociologically-minded theorist would appreciate, in all cases it is apparent that within these areas of expertise decisions would be made which are politically momentous, and in particular, would encompass some of what is regarded as constitutional law (the foundational, difficult to change, law of the state). Therefore, though judges are special experts in carrying out this momentous, politically contentious law-making by employing a different means than would "ordinary" elected law-makers (i.e. the principled technique of abstract theory formation and argument), this law-making is nonetheless still political. What is indicated is a restriction of candidates for theorydriven adjudicative law-making to judges and lawyers. But as even Dworkin acknowledges, these law-makers have political views, as conservatives, liberals, and so on, political views which are perfectly appreciable to the voter. Given the foundational commitment to a democratic/representative foundation for the legitimacy of government, candidates for judicial office (at least for any judicial office whose decisions involve constitutional law-making) should be elected to office.

It is worth pointing out here that adopting such a suggestion does not represent a transition in the direction of majority rule in derogation of the protection of the rights of political minorities. Adjudicative law-making bodies like Supreme Courts or the House of Lords operate, no less than legislatures, on the basis of majority rule. If five out of nine judges on the Supreme Court of Canada or three out of five Law Lords 
favour your argument, you win. It is the constitution that protects, or not, the rights of political minorities, although typically the protection of minorities is basically afforded by the constitutional protection of all individuals by the institution of certain inviolable rights. So, to the extent that constitutional law ensures that political minorities do not suffer, this flows from the substantial rules of the constitution - it has nothing to do with minority weighting in the adjudicative institutions that make constitutional law. It is the case, however, that certain constitutions like that of the US require that legislative constitutional law-making require more than simple majorities, but that is not our present concern.

So, to summarize the conclusions so far: on both the naïve positivist and the theoretical expertise characterizations, officials of bodies which have significant adjudicative law-making power in the realm of constitutional law should be popularly elected. The difference in specifics arising from the different characterizations of judicial expertise is that on the naïve positivist view, officials in these bodies need not be legally trained at all - they are adjudicative law-makers whose legitimacy arises by their democratic/representative election, though since they are making law interstitially as they resolve conflicts in actual cases, they will require the expert assistance of judges or lawyers to assist them in the correct formulation of their views. Since such an adjudicative body would undoubtedly be regarded as of significant political and legislative importance, it might be regarded as appropriate to require that their legal advisors or clerks be drawn from the most senior ranks of the legal profession. Indeed, one might envisage the position of Clerk to the Constitutional Council as being the most senior position in the judiciary.

On the theoretical expertise view, while the members of higher courts or the highest court dealing with such issues would likewise be popularly elected, the possible candidates would be restricted to members of the legal profession. Standards for qualification as candidates might turn on length of time in practice, judicial service, and so on, or the qualification might be minimal, having acquired a law degree and professional qualification, for instance. On the latter, minimal standard, judgments as to a candidate's experience and its importance are regarded as a matter of political judgment left to the electorate; on the former, judgment on that issue would be denied it.

From the perspective of legal cognition, the ultimate conclusion is essentially identical to that which follows from the position of naïve positivism, but for different reasons. From this perspective, judicial expertise is a kind of moral expertise, an artificial reason directed to the exploration of basic moral concepts and to their elaboration, and systematisation of norms anchored by them, through the adjudication of actual cases in context. Thus judicial expertise is bounded by the scope of basic moral concepts. There is thus a natural limit on judicial expertise. Importantly, it seems plausible to say that it does not stretch into areas of political morality which underpin (if any truly moral considerations underpin) the sort of norms that govern constitutional law. The point of saying this is not to deny that there is such a thing as political morality. Clearly, political systems are unjust in so far as they direct actions towards individuals or groups in ways which are immoral - by harming them in various ways 
or killing them, by depriving them of property, and so on. Political institutions no less than other institutions can behave more or less morally. But there seems no good reason to suppose that the sorts of considerations that underpin various sorts of modern political systems, such as democracy, equality, liberty, solidarity, and so on, are matters of innate conceptual cognition. Rather, as mentioned above, these sorts of considerations arise as a matter of historical achievement. Indeed, it seems plausible to think that most of these values have been realised despite, rather than because of, our basic cognitive capabilities. To the extent that there is a universal grasp of basic "political" concepts, i.e. concepts which tend to shape attitudes toward social and political organization, the concepts are ones of status, hierarchy, in-group and outgroup, and a sexual division of labour. ${ }^{38}$

From this perspective, political "morality" is not moral in the sense that it derives its meaning from basic moral concepts, but is rather a matter of the critical assessment of various technologies of organizing power to ascertain whether and how they further the application of our moral commitments, derivative of basic moral concepts, to all members of the polity. This in large part overcomes certain typical human cognitive predilections, such as ethnophobia. Politics and political legitimacy has more to it than this, of course. Political systems are judged not only on whether they achieve acceptable standards of morality, but whether they otherwise enhance the lives of their subjects, economically, aesthetically, and so on. This is not at all to say that political morality should be modelled as the enlargement or extension of basic moral concepts such as agreement to situations where they are, if anything, fanciful, as for example might characterize social contract theories of political legitimacy. Rather it is quite the opposite - that political and social forces must be understood in a way to show how various modes of dealing with them, through certain types of institutions and other techniques, have systematic moral consequences.

From this perspective, judges simply have no particular expertise with the law of the constitution, beyond that expertise which the naïve positivist suggests characterizes their rule-book expertise of the workings of legal rules in general. Thus the attitude of one who accepts the common law cognition characterization of legal expertise should adopt the naïve positivist's attitude to the constitution of an adjudicative body empowered to make constitutional law - it ought to be popularly elected from the citizenry as a whole, though its operation should be enhanced by the advice of a senior judicial clerk.

Despite the foregoing counsel, the position adopted here is not one in favour of the wholesale popular election of judges; it proposes a jurisprudentially-developed classification of adjudicative law-makers into two camps: those who address constitutional law, and those who do not. Though all three of the characterizations of judicial expertise suggest the popular election of adjudicative law-makers in the constitutional realm, it would also appear to me that the operation of the law outside that realm favours a non-popular method of adjudicative law-maker selection. For in these areas, where judicial law-making is largely interstitial and subject to legislative correction, all three systems suggest the primary basis upon which any adjudicator 
should be appointed is expertise. In all three versions, judicial expertise is not trivial, and so the question of method of appointment turns on assessing which means of selection will deliver the most expert bench, in particular in the upper reaches of the judiciary.

I shall not address all the means which might be considered. I shall end by offering a suggestion. The goal is to fairly select those lawyers on the basis of the extent of their expertise, in some way by which the gravity and objectivity of the selection is to some extent secured. My suggestion is that such lawyers should be selected by those best able to judge their legal expertise, i.e. other lawyers. Surely that would be superior to any system of appointment by elected officials like prime ministers "subject to" the advice of some other appointed group of lawyers. The trick is to ensure that the electorate is narrow enough to ensure the electors are themselves competent judges of the expertise of candidates, but broad enough to remove any "clubby" quality to the process, i.e. the sense that there was a self-perpetuating, closed-shop system of appointment which preserved a caste of judges selected for reasons other than their capability, i.e. their sex, race, socio-economic background, political affiliation, and so on. An electorate comprising the bench, the practising bar of ten years' experience, and law professors of ten years' experience, might be a place to start. Of course, if the electorate and the pool of candidates, i.e. the legal profession, is not constituted in such a way as to allow any subset of itself selected to serve as judges to deflect some "clubby" constitution of the bench, then there is indeed something of a problem. However, that is not an issue within the scope of my ambitions here, which are focussed on the selection of judges on the basis of their expertise, so I shall leave that conundrum to others. 